\title{
Building GIS Platforms for Spatial Business: A Focus on the Science of Maximizing Location Intelligence Benefits through Risk-Cost Management
}

\author{
Christopher G. Franklin \\ University of Redlands \\ cgf@gisdatadr.com
}

\author{
Jayashree Sreedharan \\ University of Redlands \\ jayashree_sreedharan@redlands.edu
}

\begin{abstract}
A scientific decision model is simulated for rigorously aggregating weighted risks and costs for lower-order risk factors established by Tomlinson for planning GIS (Geographic Information System) implementations. The basic assumption of the paper is that generally, management practitioners do not estimate risk with the required quantitative rigor during the planning phases. Examples include: (a) lack of Johari window risk mapping and assessment (b) subjective versus Delphi method judgmental probabilities (c) violation of Lusser's law (d) failure to utilize Galton's estimation (e) incorrect weighting (if at all) (f) doubtful risk aggregation techniques for summarized likelihoods and ( $g$ ) ad hoc decision making without Bayesian logic. For organizations competing in a global economy, strong decision models lead to management decision-making options in the creation of value from location awareness and proximity intelligence capabilities. Results are simulated and discussed with reference to future potential research.
\end{abstract}

\section{Introduction}

The paper is a work-in-progress that has evolved from teaching senior graduate business students. It is an attempt to answer their GIS (Geographic Information System) implementation questions. For example, (a) how to identify risk factors as recommended by Tomlinson [1], the "Father of GIS" [2] (b) how to assign, manipulate and develop a dynamic "likelihood of success" point-estimate for the overall project (temporally monitored throughout the planning, execution and final implementation stages).

According to Tomlinson, planning GIS implementations firstly requires a robust evaluation i.e., risk assessment [53] of the IT/IS management ecosystem. For example, what are the forcings resisting change? Are they a knowledge gap, project scope, schedule, cost, or planning capabilities? Secondly, rigorous estimation i.e., risk analysis, of the risk probabilities of: "technology, organizational functions, organizational interactions, constraints, stakeholders, overall complexity, project planning, project management [52], project scheduling and project resources" [1].

Additionally, these critical categorical factors are comprised of sub-factors, each with their own probability risk occurrence forcings, for a total of twenty-two risk occurrence factors in the Tomlinson framework for planning a GIS implementation.

Although Tomlinson discusses the need to "score" the likelihood of achieving all of your information products through sub-risk factor outcomes for ultimate upper management decision making, he does not offer detailed insights into the proper theoretical, mathematical and statistical methods required and available to do so e.g., Johari window [6], Delphi method [9], Lusser's law [3], Galton's Vox Populi [13], Weighted Risk Factoring (WRF) [14], Bayesian networks [24] and so on.

Absent also from such discussions is any explanation on how to correctly weight the risk values e.g., WRF technique [47] or how to project risks dynamically across a project's temporal domain [42].

If a practitioner, in an attempt to get a Tomlinson "project score", adds up the risks and averages them that is woefully incorrect [3] and will lead to highly underestimated risks. However, no two GIS implementations are identical, especially in complex IT/IS ecosystems. "If the proven technology cannot create more than 80 percent of your information products, you are in a very high-risk category" [1].

Thus, the paper makes an attempt to describe a rigorous and robust modeling approach that correctly manages data and information to improve GIS products [43]. This should lead to innovative downstream benefits flowing from creating value around powerful location awareness and proximity intelligence insights (i.e., Location Intelligence).

Fischhoff [40] describes the risk-cost-benefit process. All "...innovative technologies share a property: Their effects must often be inferred long before they are experienced. If those inferences are sound, then informed decisions are possible. If not, then decision-makers may incur risks and costs far greater than any expected benefits. Risk, cost and 
benefit analysis can offer transparent ways to assemble and integrate relevant evidence to support complex decision-making. All forms of analysis have the same logic: Decompose complex systems into manageable components and then calculate how they might perform together. All require scientific judgement to bound the set of components and assess the limits to those bounds. All require ethical judgement to determine which outcomes to predict and to extract the policy implications of the results. The usefulness of any analysis depends on how well its underlying assumptions and their implications are understood by those hoping to use its results" [4].

\section{Research Questions and Hypothesis}

The following research questions and hypothesis inform the investigation in this paper.

RQ1: Can effective solutions to modeling risk complexities be unified for a robust and rigorous GIS implementation?

RQ2: How can risks be better delimited and mitigated throughout a GIS implementation?

RQ3: Given the forcings of risk, operating hierarchically, can we predict an overall probability of risk occurrence for a GIS implementation project?

HYPOTHESIS: Risk forcings can be delimited and mitigated into one overall probability of occurrence.

NULL HYPOTHESIS: Risk forcings cannot be delimited and mitigated into one overall probability of occurrence.

Is there an effective approach to modeling risk complexities that can lead to better cost-benefit analysis? This area of investigation seems to offer an innovative approach to the pursuit of a robust GIS implementation, which likely would contribute to a stronger foundation for optimizing long-term location intelligence benefits.

\section{Theory Review}

\section{A. The Johari Window}

What is a Johari window? It is a cognitive quadrant system to initially position what is known and what is not known about a phenomenon e.g., the risks of a GIS implementation. This categorical quadrant applies well to the initial risk assessment of the factors that are involved in the risk management function. Both the Johari window and the Delphi method are beyond the scope of a detailed discussion in this paper, nevertheless they are important to briefly describe and reference.

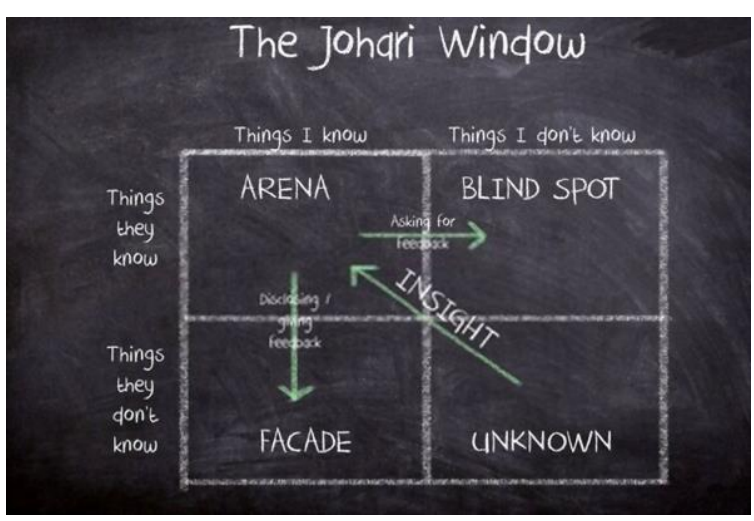

Figure 1 The Johari Window

(a) Known-Knowns are things, we know, we know (b) Known-Unknowns are things we are aware of but do not know (c) Unknown-Knowns are things unknown but knowable and finally (d) UnknownUnknowns are things unknown to us, and unknown in terms of whether they are even knowable [6].

Before convening a Delphi expert panel, it may be prudent to utilize a cognitive science approach (i.e., the Johari window), to gain insight and think thoroughly about all risks, especially in the context of "unknown-unknowns".

These techniques are not new. They have been used by intelligence agencies and larger organizations in their strategic planning cycles and are common in Operations Research and Project Management literature [7], [49].

\section{B. The Delphi method}

We utilize the Rand Delphi method to assign risk occurrence probabilities. The Delphi method is well proven and does not require a detailed analysis in this paper. Sufficient references are provided to allow practitioners to utilize this method to establish the necessary initial judgmental probabilities for each line-item risk sub-category. The simplified "miniDelphi method" is recommended to practitioners as an appropriate probability-of-risk occurrence generating method [8].

"The Delphi method or Delphi technique (also known as Estimate-Talk-Estimate or ETE) is a structured communication technique or method, originally developed as a systematic, interactive forecasting method which relies on a panel of experts" [8]. 
"Delphi is based on the principle that forecasts (or decisions) from a structured group of individuals are more accurate than those from unstructured groups" [9] e.g., GIS implementation analysts and IT experts.

"The Delphi method was developed by Project Rand during the 1950-1960's (1959) by Olaf Helmer, Norman Dalkey and Nicholas Rescher" [11]. "The technique can also be adapted for use in face-to-face meetings and is then called mini-Delphi or EstimateTalk-Estimate (ETE)" [12].

By randomly iterating the risk values or "judgmental probabilities" using the Excel "RAND()" function, a hypothetical five-person Delphi panel [10] is created (e.g., three external expert analysts and two internal organizational expert analysts) following the "mini-Delphi" approach i.e., face-to-face versus anonymous questionnaires.

"Delphi has been widely used for business forecasting and has certain advantages over another structured forecasting approach, prediction markets" [9].

\section{Galton - Vox Populi}

The term "Vox Populi" [13] (i.e., Latin for 'voice of the people' (i.e., wisdom of the crowd) was coined by Sir Francis Galton to describe the effect where the median "guess" of a crowd was closer to the actual value than any individual guess. Galton's Vox Populi and "Wisdom of the Crowd" concepts are widely utilized [17]. Galton preferred using percentiles and the median over different types of mean [16]. This Vox Populi/Wisdom of the Crowd concept is also seen used in courts of law i.e., trial by judge or jury, i.e., 1 vs 12 individuals.

\section{WRF Technique}

The "Weighted Risk Factor" (WRF) cost weighting estimation technique has been effectively used to determine project budgets and weightings. Risk-Weighted cost estimates for projects using this method provide an essential link between Project Risk Management [55] and Financial Risk Management decision making [14].

\section{E. Lusser's Law}

The theory of reliability of systems and the probability product law of series components are well understood in reliability engineering theory [18] through the work of Robert Lusser [3]. Lusser's Law is also known as the probability product law for a series of components.

Dr. Eric Pieruschka and his mathematicalstatistical observations, given to Dr. Werner Von Braun regarding testing failures of the $\mathrm{V}-2$ rocket during the 1940 's, were a precursor to Lusser's work [36].

Lusser showed that a system of components (e.g., a rocket) was less reliable than its most unreliable components i.e., $1 / \mathrm{x}^{\mathrm{n}}$, a view that was not widely held. In fact, in non-reliability disciplines and theory domains, even today, many researchers and practitioners incorrectly believe overall reliability is simply an average of the reliability of the individual components.

$$
R_{s}=r^{N}
$$

\section{Figure 2 Eric Pieruschka's Formula}

"For example, given a series system of two components with different reliabilities - one of 0.95 and the other of 0.8 - Lusser's law will predict a system reliability of 0.76 which is lower than either of the individual components." [37] The dramatic effect of this principle when there are 1000's of components should now be understood.

$$
R_{s}=0.95 \times 0.8=0.76
$$

"Simple mathematics of probability states that the overall reliability equals not the average, as some may believe, but rather the product of the reliabilities of the individual components: $P_{\text {overall }} * P 1 * P 2 * P 3$ ...Pn; where P1, P2, P3 etc., are the individual reliabilities of each of the " $n$ " components. This simple reliability formula is based on the following basic rule of probability: "If P1 is the probability that an event, $E_{1}$, will occur, and $P 2$ is the probability that event $E_{2}$ will occur, then $\mathrm{P} 1 * \mathrm{P} 2$ is the probability that both events will occur" [3]. Two notable references on reliability theory and its mathematical and statistical foundations are [19] and [20].

In this paper, reference is made to the "likelihood of success", not to "risk" or "reliability". Values from 0.00 to 1.00 are the probability for the occurrence of risk, and are established by the Delphi method. A probability of occurrence for a risk of 0.20 can also be expressed as the complement, $(1.0-0.2=0.80)$ i.e., as an $80 \%$ "likelihood of success" for a particular risk factor. Conceptually within organizations managers and practitioners find it easier to conceptualize a 
positive rather than a negative (i.e., "likelihood of success" versus probability of occurrence) [21].

The following explanation shows how mathematical reliability theory [18], [19] and the probability product law of series components [3] are important and can be applied to the aggregation of multiple hierarchical risk factor categories in combination with the "wisdom of the crowd" technique (i.e., median value) both hierarchically within categories and horizontally across categories of risk; to establish a dynamic overall risk pointestimate of a GIS implementation throughout the project.

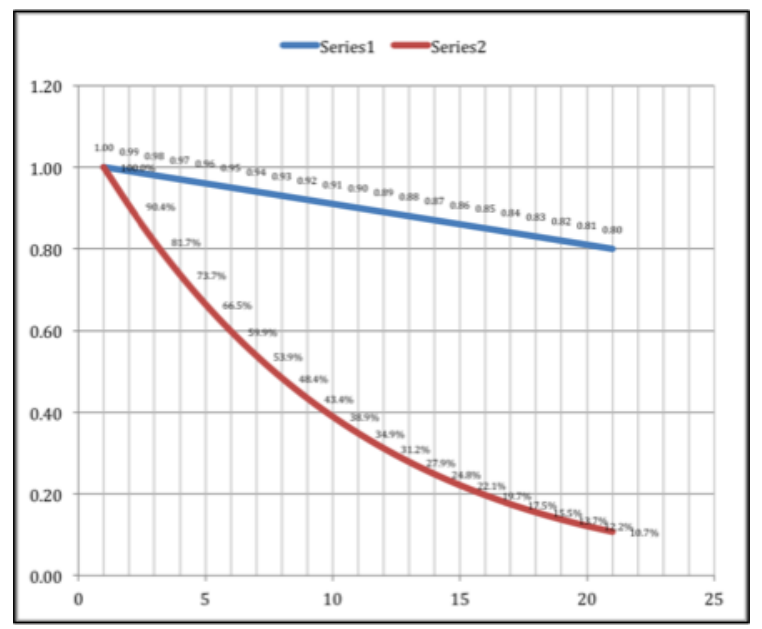

Figure 3 Probability of Success for a 1 to 10 risk factor system

A simple example will illustrate the important non-intuitive insight these methods provide.

Assume a system with 10 risk factors, each risk factor has the same "probability of occurrence", say 0.20. Convert this to its compliment, i.e., the "likelihood of success" which is $1.0-0.2$ or 0.80 . This becomes an $80 \%$ "likelihood of success" for each risk factor. Then by executing the EXCEL function "=POWER $(0.80,10) "$ we can visualize the "likelihood of success" as the red negative exponential curve. Figure 3 shows scenarios from $100 \%$ "likelihood of success" down to $80 \%$. Where 0.80 multiplied by itself 10 times is equal to 0.107 or $10.7 \% \quad($ not $\quad 80 \%) \quad$ e.g. $(.8)(.8)(.8)(.8)(.8)(.8)(.8)(.8)(.8)(.8)$ or $0.80^{10}$.

Therefore, the "likelihood of success" for the 10 combined risk factors has dropped from $80 \%$ for a system with one risk factor to just $10.7 \%$ for a system with 10 risk factors all still at $80 \%$. Going back to the probability of risk occurrence by taking the compliment gives $1.0-0.107$ or 0.893 , not 0.20 . This is not intuitive yet dramatically impacts risks.
Clearly those who believe the "system" probability is simply the average of $(10 \times 0.80) / 10$ or " 0.80 " are significantly overstating the likelihood of success (or severely understating the probability of risk occurrence). Understating the occurrence of risk in this example with all of the subsequent management decision errors, costs and lack of benefits, such a mistake would have in a GIS implementation, demonstrates how potential benefits can evaporate.

This example shows the need for a rigorous and robust use of precise mathematical statistics and probability theory, when assessing the likelihood of a of GIS implementation's success and of determining those likelihoods throughout the implementation period.

Figure 3 shows how the theory of reliability and the probability product law of series components [3] must be applied correctly to the aggregation of risk factors in a GIS implementation system.

We are guided by Tomlinson's 80/20 (likelihood of success/probability of risk occurrence) and use an $80 \%$ overall threshold for a minimally acceptable overall project likelihood of success. Clearly obtaining a higher likelihood of success, perhaps $90 \%, 95 \%$ or even higher is very desirable. However, as can be seen in this simple example, it is very difficult to achieve and is non-intuitive.

\section{F. Bayes Theorem and Monte Carlo Method}

These two methods have been well described in the literature and beyond the scope of a detailed analysis in this paper. However, both methods are incorporated into this decision model. Bayes provides the statistical conditional probability power [38] and Monte Carlo provides the law of large numbers to support strong expected random variable values [50] close to the theoretical mean [44]. Two references are provided for those wishing a more complete discussion and explanation [38], [35].

\section{The Decision Model}

In this paper we focus on an innovative hierarchical approach to modeling. We refer formally to the model as the Hierarchical Ensemble Lowerorder Probability risk model or HELP for short. The HELP model "helps" practitioners correctly calculate and aggregate sub-category (i.e., lower-order) risk factors. "To ensure a successful GIS implementation, you must thoroughly evaluate the risks associated with your implementation strategy" [1]. A lowerorder risk factor example would be "Is the technology being adopted new?". This lower-order risk factor, 
adjudicated by a Delphi panel of experts, might then be rolled-up with other lower-order risk factors to form a category risk factor, such as those risks associated with "Technology". This in turn is aggregated with all categories of risk to provide the much-needed indication of overall likelihood probability of success for the GIS implementation.

The HELP model approach is built on firm mathematical theory and statistical principles. Despite being robust, HELP can easily be implemented as a simple EXCEL (Microsoft) application. Stronger cloud platform services [26]

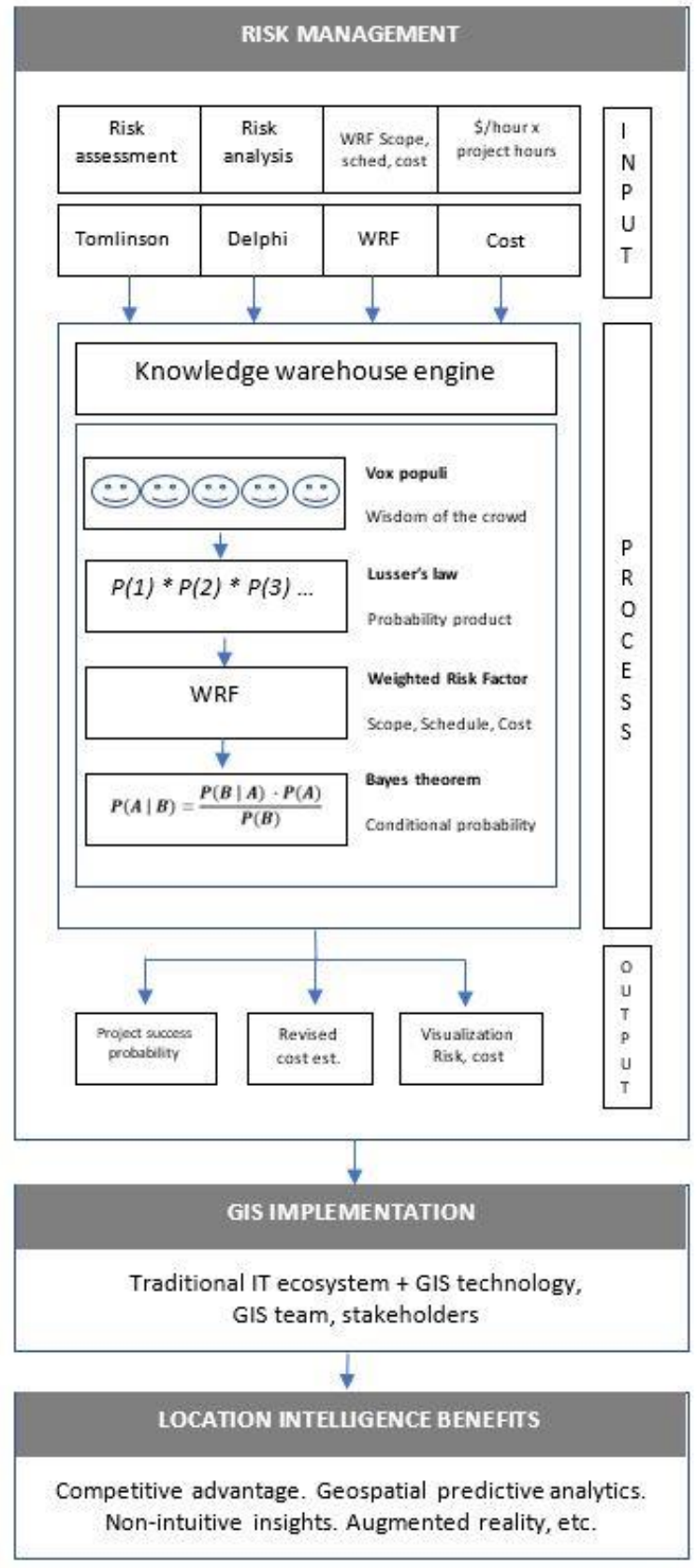

Figure 4 Conceptual Process Flow Model using modern languages like Python are currently being tested.

With respect to the traditional GIS project management "benefit-cost" analysis [40], [41], [4], typically used by planning practitioners [22], [24] or the less robust "cost-benefit" analysis method [23], the decision model conceptually inverts the BenefitCost/Cost-Benefit analysis process into a strict RisksCosts-Benefits inverted triangle (Risk=top, Cost $=$ middle and Benefit $=$ bottom) hierarchy.

Each of the three components of analysis from the top down (i.e., Risks, Costs, Benefits), is derivative of the preceding component. This achieves a more rigorous and delimited assessment of risk "first" based on initial conditions before any premature distraction or consideration is made of costs or benefits. Only when risks are fully delimited can a discussion of costs begin and only after that rigorous analysis can any opening investigations be made regarding potential benefits.

There are four primary inputs to the model: Risk Assessment, Risk Analysis, Weighted Risk Factors and Budgeted Resources funnel into the model's Knowledge warehouse engine [25]. Risk Assessment, is Tomlinson's 10 key factors and 22 sub factors). Risk Analysis assigns a probability of occurrence i.e., Delphi likelihood of risk occurrence values. WRF (Weighted risk factor) technique creates weighted global adjustments for (i) Scope (ii) Schedule and (iii) Cost constraints. Budgeted Resources i.e., provides the budgeted and approved financials for the GIS implementation (NB: in this paper we use only budgeted time and billable hourly consulting rates to "demonstrate" costs).

Finally, the Bayes theorem [34], [42] component offers powerful processing logic for posterior conditional probability solutions and projections i.e., $\mathrm{P}(\mathrm{A} \mid \mathrm{B})$, based on the inputs mentioned above. Bayesian calculations generate accurate, non-intuitive updates to project risk and cost variances against actuals throughout the project. This decision model contributes to the delivery of higher quality location intelligence benefits built on a highly functional and pristine GIS implementation.

An example of a lower-order risk factor from Tomlinson's examples would be: "Is the technology being adopted new?" This lower-order risk factor (i.e., adjudicated by a Delphi panel of experts and resolved by Galton's median estimate), is rolled-up hierarchically using Lusser's law with other "children" lower-order risk factors to form a nested "family" category. Then the families are rolled-up into "neighborhood". The "neighborhood" is the likelihood probability of success for the overall GIS implementation. 


\section{Assumptions}

The decision model consists of five inputs that are all assumed to be correct. Those are (a) Tomlinson's risk factors (b) Delphi's probability of risk occurrence (c) WRF's global weighted scope, schedule and cost constraints (d) approved Budgeted resource allocations and (e) delimited parameter ranges to achieve a minimum acceptable "likelihood of success" threshold of $80 \%$.

\section{Excel Developer Panel}

This simplified Microsoft Excel developer panel showing only four of the ten risk categories, demonstrates the workflow, as shown in Figure 5.

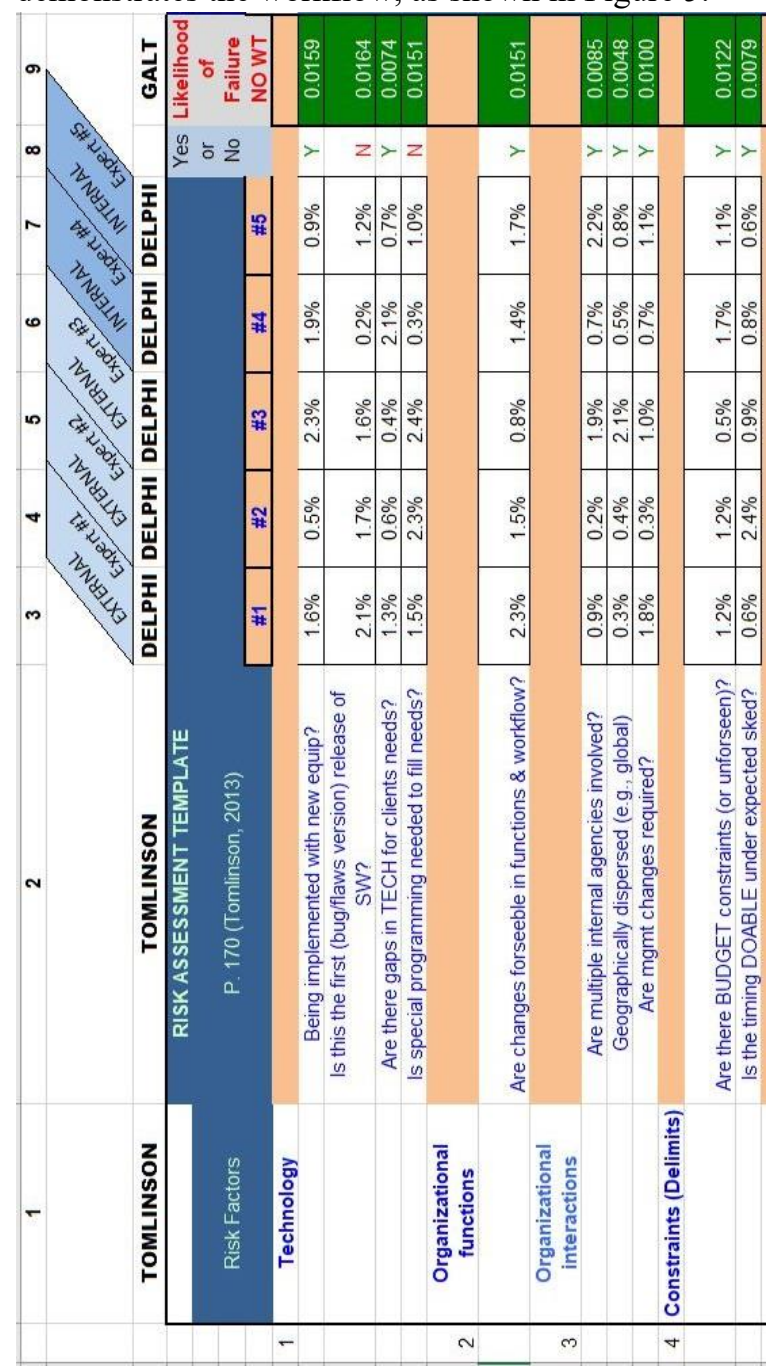

Figure 5 Excel sheet - Delphi method
Once the judgmental probabilities for each of Tomlinson's twenty-two risk factors are obtained from the Delphi method, Galton's "Wisdom of the crowd" logic is applied [13]. (i.e., the Delphi is parametrically adjustable e.g., risk of occurrence ranging from $1 \%$ to $3 \%$ for mitigated risk factors as required), This would create a point estimate for each probability of "risk occurrence" (e.g., 0.01 to .03) for each risk factor subcategory.

The Delphi method can of course produce a point estimate probability of risk occurrence anywhere from 0.00 to 1.00 for each of Tomlinson's 22 GIS implementation strategy risk sub-factors. However, the likelihood of such high-risk rates aggregating to meet the minimum $80 \%$ overall project threshold is negligible.

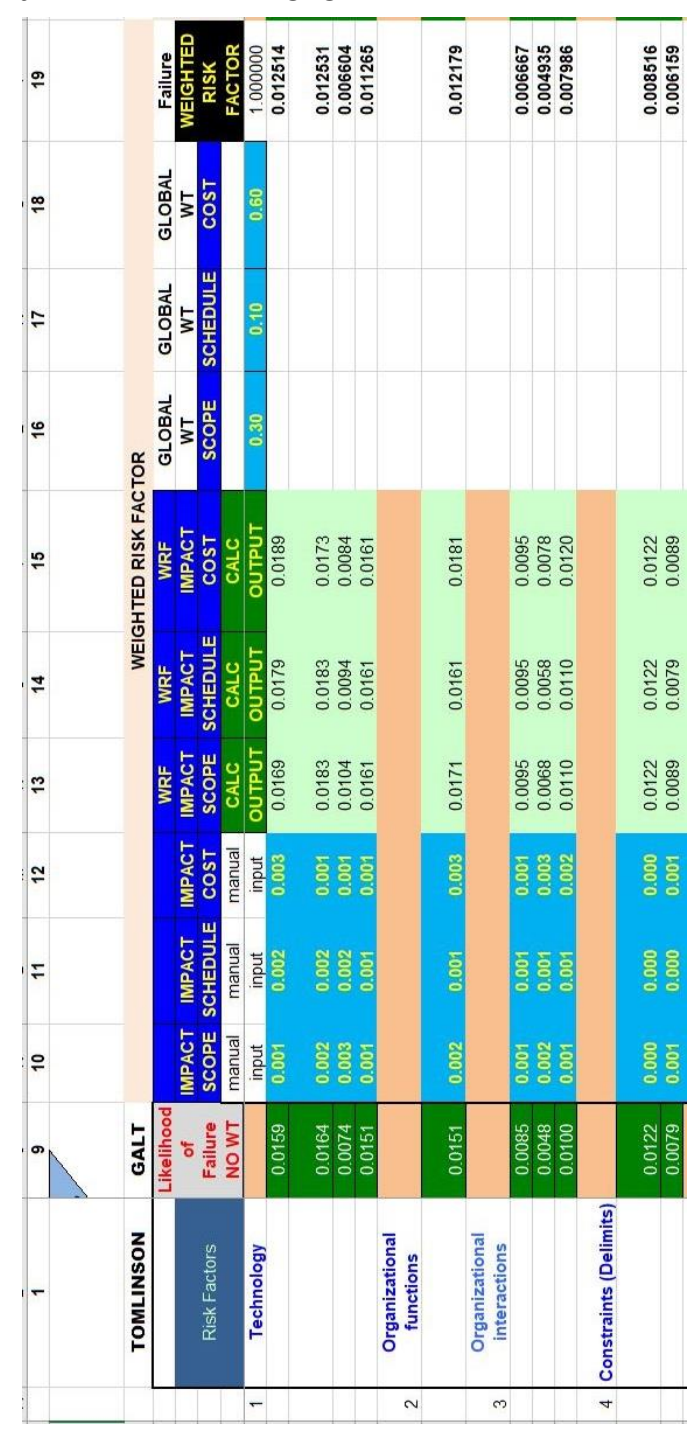

Figure 6 Excel sheet - WRF technique 
A word about Delphi's subjective probability: "In a risk analysis, the word subjective may have a negative connotation. For this reason, some analysts prefer to use the word personal probability, because the probability is a personal judgment of an event that is based on an expert analyst's best knowledge and all the information, she has available. The word judgmental probability is also sometimes used. To stress that the probability in the Bayesian approach is subjective (or personal or judgmental), we refer to the analysts or her/his/your/my probability instead of "the probability" [55].

Galton's estimation, based on "wisdom of the crowd" takes the five Delphi estimates and produces a point estimate for the risk sub-factor from the "five experts" in column 9 .

Next the WRF technique is applied to the Scope, Schedule and Cost constraints of the implementation. Values of these are input based on the WRF procedures. Then the WRF applies formulations to the WRF input estimates (columns 10,11,12). Those computations create columns $13,14,15$. With final inputs for the global weighting desired in columns $16,17,18$, adjusted Galtonian median values are calculated and presented in column 19 in Figure 6.

The model then dynamically summarizes the compliment (i.e., 1-probability of risk occurrence) to find the "likelihood of success" (i.e., 1-risk) using Lusser's law and rolls-up those subcategory probabilities into 10 major risk categories. They are then passed to Bayes theorem that incorporates them into a prior distribution of budgeted resource calculations, (specifically number of billable consulting hours times the various hourly rates). Next the Bayesian compartment of the model takes the values for the budgeted resources as input into column 21, as a prior distribution of expected and budgeted consulting hours $\mathrm{P}(\mathrm{A})$ by risk category rows (Technology, Organizational functions and so on). Then probabilities for each of the prior distribution expected and budgeted consulting hours $\mathrm{P}(\mathrm{A})$ by risk category, are calculated. Next the $\mathrm{P}(\mathrm{B} \mid \mathrm{A})$ for column 23 is calculated based on the WRF values in column 19 and the values in column 22. Column 24 is calculated on the assumption that as risk increases, the number of hours increase. A parametric factor offered for adjusted hours [i.e. (1/likelihood of success) $x$ prior hours] to improve the posterior distribution. The $\mathrm{P}(\mathrm{B} \mid \mathrm{A}) \mathrm{P}(\mathrm{A})$ is calculated by multiplying column 22 and 23 . The $\mathrm{P}(\mathrm{B})$ is determined using column 25 to yield posterior cost adjustments in column $26 \mathrm{P}(\mathrm{A} \mid \mathrm{B})$.

Finally, the graph in Figure 7 is a dashboard visualization of the posterior, prior and sum of the two cost estimates for each risk category. By inputting expected prior budgeted resources a posterior cost distribution is output, using Bayes' theorem.

The Excel developer panel (i.e., future dashboard) works well and displays all weighted risk factors for summarized categories of risks as well as overall risk assessments [54] for all temporal phases (i.e., from planning to execution) of the GIS implementation project and a graphical visualization.

The planning process usually begins with an initial Johari window analysis [6] before seeking judgmental probabilities created using the Delphi method [8].

Lusser's law rolls-up those subcategory probabilities into 10 major risk categories. They are then passed to Bayes theorem that incorporates them into a prior distribution of budgeted resource calculations, specifically number of billable consulting hours times the various hourly rates. The model then dynamically summarizes the compliment (i.e., 1-probability of risk occurrence) to find the "likelihood of success" (i.e., 1-risk).

Lastly, a Bayesian prior/posterior analysis of time and billable rates is performed with adjustments noted. The model is a robust and a dynamic risk-cost modeling application that combines disparate theories from mathematics and statistics to aggregate risks [56].

\section{The Results}

In terms of the GOST criteria approach [60]: The goal of the paper is to contribute toward improving GIS location intelligence benefits. The objective of the paper is to focus on improving GIS implementation efficiency and effectiveness through the lens of "risk". The main strategy is to focus on measuring the magnitude of risk impacts in the planning phase. One tactic is to aggregate hierarchical and heterogeneous risks, across all complex risk domains, and manage the permutations of eliminating and/or mitigating hierarchical and heterogeneous risks, for success of the whole project.

The results demonstrate this can be achieved. The results also indicate the need for further study and research into expanding this capability in this little studied niche of GIS.

In response to the research questions, to date we can report as follows:

RQ1: Can effective solutions to modeling risk complexities be unified for a robust and rigorous GIS implementation? 
We judge that the HELP model ensemble methodology is powerful and capable of not only modeling risk complexities but extending the model to quantification of costs. Future research should attempt to move the model toward benefit quantification.

RQ2: How can risks be better delimited and mitigated throughout a GIS implementation?

We judge the model ensemble methodology is powerful and capable of "dynamic" control of risk inputs and calculations to assist in decision making throughout the temporal domain of a project.

RQ3: Given the forcings of risk, operating hierarchically, can we predict an overall probability of risk occurrence for a GIS implementation project?

One of the strengths of the model is its ability to federate an accurate point estimate of the likelihood of success for the implementation project as a whole.

HYPOTHESIS: Risk forcings can be delimited and mitigated into one overall probability of occurrence.

We can isolate and control risk forcings and identify their effects on "cost" in the planning stages before any sunk cost decisions. An extension of this model may have to be developed to go further past costs and identify effects on benefits.

NULL HYPOTHESIS: Risk forcings cannot be delimited and mitigated into one overall probability of occurrence. The null hypothesis is shown to be false.

More research is needed on the extension of costs to short, medium and long-term benefits.

\section{Summary}

Risk decision modeling needs to be well understood by practitioners operating in a global competitive marketplace. "The impact of risk modeling accuracy on cost-benefit analysis", [61] is fertile ground for applying the GOST criteria approach [60]. Just as theory i.e., location awareness [28], [29], [27] and proximity intelligence [30], [31], [32], [33] inform Location Intelligence; robust and pristine GIS implementations become a necessary and sufficient condition to inform organizations attempting to create spatial value for innovative advantage [39].

\section{Conclusion}

Tomlinson [1] provides the empirical rationale for the risk decision model developed in this paper. Empirical evidence supports the model concept [15], [5]. Figure 7 visualizes the cost (y-axis) effects of 10 categorical risks (x-axis) for the project as a whole for prior, posterior Bayesian analysis.

The following research questions and hypothesis may be helpful for future research and investigation. $R Q 1$ : Can risks be correlated to costs and benefits? $R Q 2$ : Is there causality between risk and cost? RQ3: Can risk-cost-benefits be accurately forecast? HYPOTHESIS: A reduction in risk correlates to a reduction in costs.

NULL HYPOTHESIS: A reduction in risk does not correlate to a reduction in costs.

Location Intelligence requires a robust Geographic Information System (GIS) which includes spatial data, processes and technology [58]. The successful implementation of GIS involves integration and collaboration with existing IT (Information Technology) systems and teams. It is not inexpensive, but the subsequent benefits of GIS applications can outweigh the costs [47]. In order to achieve such a robust system, there must be ongoing rigorous risk analysis [51] during planning, implementation and operational phases to optimize location awareness and proximity intelligence value [45], [46] using predictive analytics [57].

Future research should focus on exploring meteorological analogs like "sensitive initial conditions' and "ensemble forecasting" [59] as well as enhanced Bayesian Monte Carlo methodologies [24], [48].

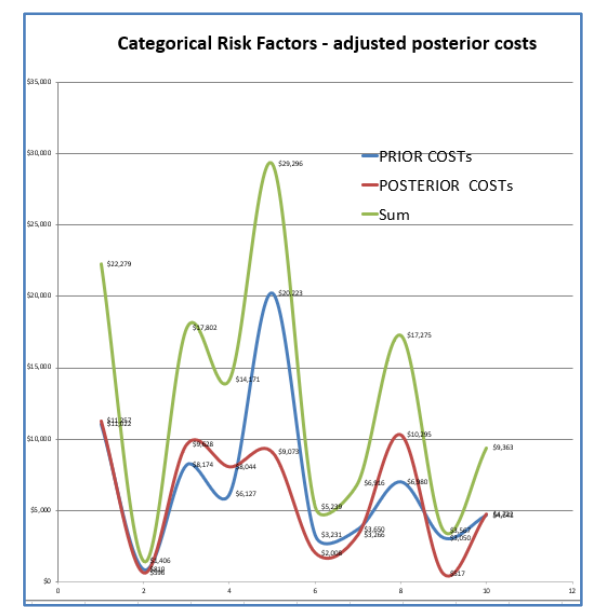

Figure 7 Risk - Bayesian Cost Correlations

In conclusion, "If the model developed in this paper does nothing else, it does demonstrate vividly...", the effect of risk "components" on a "system" such that the system is always weaker than the weakest component [37], [33]. 


\section{References}

1. Tomlinson, R. F. (2013). Thinking about GIS: geographic information system planning for managers (Vol. 1). $5^{\text {th }}$ Edition, ESRI. Pp. 170.

2. Rura, M. J., Marble, D. F., \& Alvarez, D. (2014). In memoriam: Roger Tomlinson - "The Father of GIS" and the transition to computerized geographic information. Photogramm Eng Remote Sens, 80(5), 400-401

3. Lusser, R. (1954). Reliability of guided missiles. Redstone Arsenal, Statistical Engineering Symposium, p. 44, Maryland.

4. Fischhoff, B. (2015). The realities of risk-cost-benefit analysis. Science, 350(6260)

5. Adner, Ron, (2006). "Match Your Innovation Strategy to Your Innovation Ecosystem - The Idea in Practice" HBR Spotlight, Harvard business review, HBSPC, 84(4), 98. Boston, MA, pp. 1.

6. Luft, J.; Ingham, H. (1955). "The Johari window, a graphic model of interpersonal awareness". Proceedings of the Western Training Laboratory in Group Development. Los Angeles: University of California, Los Angeles.

7. Courtney, H., Kirkland, J., \& Viguerie, P. (1997). Strategy under uncertainty. Harvard business review, 75(6), 67-79.

8. Dalkey, Norman; Helmer, Olaf. (1963) "An Experimental Application of the Delphi Method to the use of experts". Management Science. 9 (3): 458-467. 1963.

9. Rowe, G., \& Wright, G. (2001). Expert opinions in forecasting: the role of the Delphi technique. In Principles of forecasting (pp. 125-144). Springer, Boston, MA.

10. Green, K., Armstrong, J. S., \& Graefe, A. Methods to elicit forecasts from Groups.

11. Rescher, N. (1998). Predicting the future: An introduction to the theory of forecasting. SUNY press.

12. Reference Note - Informational antidotal comments obtained from: Wikipedia contributors. (2021, February 2). Delphi method. In Wikipedia, The Free Encyclopedia. Retrieved 16:10, February 18, 2021: https://en.wikipedia.org/w/index.php?title=Delphi_method\& oldid $=1004396972$

13. Galton, F. (1907). Vox populi. Nature, 1907.

14. Noor, Iqbal, (2004) "Project Management conference Risk-weighted cost estimates principles and practical applications", NASA.

15. J.G, T.R., G.U, (2020). "Prototype Development Proposal for ' $X$ ', University of Redlands, December 21, 2020, unpublished.

16. Galton, F. (1907). The ballot-box. Nature, 75(1952), 509-510.

17. Galton, F. (1907). One vote, one value. Nature, 75(1948), 414-414.

18. Barlow, R. E. (2003). Mathematical reliability theory: from the beginning to the present time. In Mathematical and Statistical Methods in Reliability (pp. 3-13)
19. Barlow, R. E., \& Proschan, F. (1996). Mathematical theory of reliability. Society for Industrial and Applied Mathematics.

20. Samaniego, F. J. (2007). System signatures and their applications in engineering reliability (Vol. 110). Springer Science \& Business Media.

21. Froman, L. (2010). Positive psychology in the workplace. Journal of Adult Development, 17(2), 5969.

22. Obermeyer, N. J. (1999). Measuring the benefits and costs of GIS. Geographical information systems, 2, 601-610.

23. Zerbe, R. Dively (1994): Benefit Cost Analysis: In Theory and Practice. New York.

24. Yet, B., Constantinou, A., Fenton, N., Neil, M., Luedeling, E., \& Shepherd, K. (2016). A Bayesian network framework for project cost, benefit and risk analysis with an agricultural development case study. Expert Systems with Applications, 60, 141-155

25. Henson, W. E., Garth, R., \& Franklin, C. (2021). Facilitating Effective Utilization of Water Science Research Among Emergency Flood Responders. Open Water Journal, 7(1), 5.

26. Franklin, C.G. \& V. J. Bezak III, (2019). "Robyn ${ }^{\mathrm{TM}}$ Decision Modeling Platform: The Early Bird Gets the Worm!", Blackstone Launchpad \& Institute for Innovation and Entrepreneurship, University of Texas at Dallas, unpublished. https://robynproduction.herokuapp.com

27. Huff, D. L. (1963). A Probabilistic Analysis of Shopping Center Trade Areas. Land Economics, 39(1), 81-90.

28. Mason, J. B. (1975). Retail market area shape and structure: Problems and prospects. ACR North American Advances.

29. Applebaum, W. (1965). Can store location research be a science? Economic Geography, 41(3), 234-237.

30. Berry, B. J., \& Garrison, W. L. (1958). A note on central place theory and the range of a good. Economic Geography, 34(4), 304-311.

31. Berry, B. J. (1971). Hierarchical Diffusion: The Basis of Developmental Filtering and Spread in a System of Growth Centers", Growth Centers and Regional Economic Development, In Niles M. Hansen.

32. Rogers, E. M. (2003). Diffusion of innovations (5th ed.). New York: Free Press

33. Bass, Frank, (1969). A new product growth model for consumer durables, Management Science, 15 (5), p215-227

34. Bayes, Thomas (1763). "An Essay towards solving a Problem in the Doctrine of Chances". Philosophical Transactions. 53: 370-418.

35. Marseguerra, M., \& Zio, E. (2002). Basics of the Monte Carlo method with application to system reliability.

36. DeVale, J. (1998). "Basics of Traditional Reliability." http://users.ece.cmu.edu/ koopman/des_s99/traditiona 1_reliability/presentation.pdf

37. Critchley, T. (2014). High availability IT services. CRC Press. 
38. Viertl, R., \& Hareter, D. (2004). Generalized Bayes' theorem for non-precise a-priori distribution. Metrika, 59(3), 263-273.

39. Berry, B. J. (1967). Geography of Market Centers and Retail Distribution," Marketing Geography, Prentice Hall, p. 126.

40. Christensen, C. M. (2013). The innovator's dilemma: when new technologies cause great firms to fail. Harvard Business Review Press.

41. Flyvbjerg, B. (2006). From Nobel Prize to project management: Getting risks right. Project management journal, 37(3), 5-15.

42. Franklin, C. (2015). Space-Time Diffusion Visualization using Bayesian Inference. ICIS 2015 Best Paper Award. Pre-Conference Workshop Proceedings. 4. University of Texas at Dallas. International Conference of Information Systems. https://aisel.aisnet.org/siggis2015/4. Nov (Vol. 27, p. 2016).

43. Franklin, C. (2018). Three Essays for the Retail Planner: Spatializing Bass, Temporalizing Huff and Visualizing the Ensemble. Doctoral dissertation. Chairman Brian J.L. Berry, University of Texas at Dallas.

44. Freund, J., \& Jones, J. (2014). Measuring and managing information risk: a FAIR approach. Butterworth-Heinemann.

45. Hubbard, D. W. (2020). The failure of risk management: Why it's broken and how to fix it. John Wiley \& Sons.

46. Huchzermeier, A., \& Loch, C. H. (2001). Project management under risk: Using the real options approach to evaluate flexibility in R... D. Management Science, 47(1), 85-101.

47. Hughes, K. (2000). Implementing a GIS application: Lessons learned in a law enforcement environment. Crime Mapping News, 2(1), 1-5.

48. Khodakarami, V., \& Abdi, A. (2014). Project cost risk analysis: A Bayesian networks approach for modeling dependencies between cost items. International Journal of Project Management, 32(7), 1233-1245.

49. Lock, D. (2017). The essentials of project management. Routledge.

50. Pitt, L. D. (1982). Positively correlated normal variables are associated. The Annals of Probability, 496-499.

51. Purdy, G. (2010). ISO 31000: 2000 - setting a new standard for risk management. Risk Analysis: An International Journal, 30(6), 881-886.

52. Raftery, J. (2003). Risk analysis in project management. Routledge.

53. Rausand, M. (2013). Risk assessment: theory, methods, and applications (Vol. 115). John Wiley \& Sons

54. Rausand, M., \& Haugen, S. (2020). Risk Assessment: Theory, Methods, and Applications New Jersey John Wiley \& Sons.

55. Raz, T., \& Michael, E. (2001). Use and benefits of tools for project risk management. International journal of project management, 19(1), 9-17.
56. Rogers, D., Plante, R., Wong, R., \& Evans, J. (1991). Aggregation and Disaggregation Techniques and Methodology in Optimization. Operations Research, 39(4), 553-582. INFORMS

57. Vijay, K., \& Bala, D. (2015). Predictive Analytics and Data Mining Concepts and Practice with Rapidminer. Burlington, MA

58. Pick, J.B., Sarkar, A., and Horan, T. (2021) Spatial Business: Competing and Leading with Location Intelligence. Redlands, CA: Esri Press.

59. Lorenz, E. N. (1969). Atmospheric predictability as revealed by naturally occurring analogues. Journal of Atmospheric Sciences, 26(4), 636-646.

60. Franklin, C., (1977). G.O.S.T. Criteria Approach: Is your GOST Aligned? Air Canada - Cargo Operations, Corporate Headquarters, Place Ville Marie, Montreal, PQ.

61. Alvehag, K., \& Söder, L. (2011). The impact of risk modeling accuracy on cost-benefit analysis of distribution system reliability. In 17th Power System Computational Conference, Stockholm Sweden, August 22-26, 2011. Power Systems Computation Conference (PSCC). 